\title{
UM CURRÍCULO EM MOVIMENTO: A MÚSICA NA FORMAÇÃO DE PEDAGOGOS E NA EDUCAÇÃO INFANTIL DO DF
}

\author{
A curriculum in mouvement: the music in \\ formation of pedagogues and in childhood \\ education of Federal District
}

\author{
Un currículum en movimiento: la música en \\ la formación de pedagogos y en la educación \\ infantil en el Distrito Federal
}

\author{
Sara Paraguassú Santos do Vale \\ Universidade Federal de Juiz de Fora \\ ssaradovale@gmail.com
}

\begin{abstract}
Resumo: Este artigo apresenta os resultados de uma pesquisa concluída, que analisou os conhecimentos musicais dispostos em dois documentos curriculares do Distrito Federal: o Currículo em Movimento da educação infantil e o currículo do curso de Pedagogia da Universidade de Brasília. O estudo objetivou analisar e relacionar os conhecimentos prescritos, visando identificar possiveis relações entre os dois documentos. Considera-se a importância da formação musical oferecida aos pedagogos para que suas práticas pedagógicas com música sejam efetivas e consistentes, uma vez que esses profissionais são responsáveis por todos os componentes curriculares da educação infantil e anos iniciais, incluindo a música. Os resultados revelaram que existem potenciais relações entre os dois currículos, relacionadas às experiências sonoro-musicais. São oferecidas condições pedagógicas, teóricas e experienciais pelo currículo do curso para os licenciandos em Pedagogia, entretanto, o caráter optativo das disciplinas é um fator complicador.
\end{abstract}

Palavras-chave: Música. Currículo. Pedagogia. Educação infantil.

\begin{abstract}
This article presents the results of a concluded research, that analized the musical knowledge prescribed in two curricular documents of Brazilian Federal District: The Curriculum in Mouvement and the curriculum of Pedagogy course of Brasilia University. The study aimed to analyze and to establish relations between the knowledges presented in the documents, considering the importance of this musical knowledge to pedagogues practices, since the pedagogue is responsible for all subjects at the childhood education and primary school, including music. The study revealed potential relations between the two curricular documents, related to experience sound music. Pedagogical, theoretical and experimental conditions are offered by the course curriculum for undergraduates in Pedagogy, although, the optative status of music subjects in the pedagogues training can be a complicating factor.
\end{abstract}

Keywords: Music. Curriculum. Pedagogy. Childhood education.

Resumen: Este artículo presenta el resultado de una investigación, que analizó los conocimientos musicales en dos documentos curriculares del Distrito Federal: el Currículo em Movimento de la educación infantil y el currículo de la carrera de Pedagogía de la Universidade de Brasília. El estudio tuvo el objetivo de analizar y relacionar los conocimientos prescritos, para identificar las posibles relaciones entre los dos documentos. Se considera la importancia de la formación musical ofrecida a los pedagogos para que sus prácticas pedagógicas con la música sean efectivas y consistentes, una vez que estos profesionales son los responsables por todos los componentes curriculares de la educación infantil y de los años iniciales, incluyendo la música. Los resultados mostraron que existen relaciones potenciales entre los dos currículos en cuanto a las experiencias sonoras y musicales. Las condiciones pedagógicas, teóricas y vivenciales, las ofrece el currículo de la carrera para estudiantes de Pedagogía, sin embargo, el carácter optativo de las asignaturas es un factor de complicación.

Palabras clave: Música. Currículo. Pedagogía. Educación infantil. 


\section{NOTAS INTRODUTÓRIAS}

Como conteúdo obrigatório, a música encontra-se em todas as etapas da educação básica incluindo-se, portanto, a primeira delas: a educação infantil (EI). Como professores desse segmento, cabe aos pedagogos a realização desse currículo, abrigando na organização de seu trabalho pedagógico vivências e experiências musicais consistentes que possam ser oferecidas às crianças. Uma das premissas para a realização desse trabalho é que aos pedagogos tenha sido oportunizada uma formação musical. Este artigo apresenta os resultados de uma pesquisa que buscou relacionar os conhecimentos musicais dispostos nos currículos de dois níveis de ensino: a educação infantil e a formação de pedagogos, partindo da premissa de que é necessário haver dominio, por parte dos professores, dos conhecimentos a serem trabalhados na escola.

As aproximações iniciais da pesquisa, a partir de conversas informais com colegas professores e do levantamento de pesquisas relacionadas a essa temática, dentre as mais recentes Niéri (2014) e Viana (2016), explicitaram a dificuldade de professores unidocentes ${ }^{1}$ em trabalhar com conhecimentos musicais na educação infantil. A fala desses profissionais apontou que a insegurança e resistência para trabalhar com o conteúdo era resultado de uma formação musical insuficiente e, por vezes, inexistente. O pouco ou nenhum contato com conhecimentos musicais no decorrer da formação de pedagogos constituiu um dos argumentos que justificam pesquisa, entendendo que é necessário haver um minimo de conexão entre os dois contextos curriculares, uma vez que o professor é o agente mais próximo da realização do currículo. Conforme Bellochio, Weber e Souza (2017, p. 208-210), a

relação de professores da educação infantil e dos anos iniciais do ensino fundamental com a Música não é simples e nem está resolvida do ponto de vista da formação acadêmico-profissional e tampouco da educação básica escolar [...] Entretanto, para que esse profissional tenha maiores possibilidades de inserir conhecimentos musicais em sua prática pedagógica é necessário que ele tenha vivenciado experiências musicais e pedagógico-musicais em sua formação.

Foi essa perspectiva que conduziu a análise da prescrição de conhecimentos musicais de dois currículos: o Currículo em Movimento (CM) da educação infantil da Secretaria de Educação do Distrito Federal; e o currículo do curso de Pedagogia da Universidade de Brasília (UnB). Com base na teoria fundamentada nos dados (TFD), a análise ocorreu em duas etapas. Primeiro foram analisadas as seções referentes à música dos documentos e, em uma segunda fase, os dados foram correlacionados, a fim de identificar a possivel relação existente entre os dois currículos.

\footnotetext{
1 São considerados professores unidocentes os responsáveis por todos os componentes curriculares da educação infantil ao 5o ano do ensino fundamental.
} 
Para operacionalizar o objetivo geral da pesquisa, este foi desmembrado em três objetivos mais específicos, quais sejam:

- Analisar a proposta curricular de música para a educação infantil no Currículo em Movimento do DF, considerando as habilidades exigidas para a realização das atividades nele dispostas, por um professor unidocente da educação infantil.

- Identificar disciplinas no curso de Pedagogia da UnB que ofereçam leituras, práticas pedagógicas e reflexões acerca da educação musical que sejam paralelas à proposta do ensino de música disposta no Currículo em Movimento do DF.

- Correlacionar as propostas curriculares para o trabalho com música emergentes das análises dos dois documentos (caderno de educação infantil do Currículo em Movimento do DF e ementas disciplinares do curso de Pedagogia da UnB) a fim de compreender as relações entre o que o pedagogo recebe em sua formação e o currículo que direcionará sua prática pedagógica.

Gimeno Sacristán (2017) organiza as objetivações do currículo em fases. Em sua primeira fase está o currículo prescrito, composto por documentos orientadores e conteúdos referentes à escolaridade obrigatória. Essa é a base que estabelece os limites deste estudo. Nas análises curriculares da educação infantil ou da formação de pedagogos, embora a prática seja reconhecida em sua importância para realização de um currículo, a presente pesquisa delimitou-se ao nivel da prescrição curricular, ou seja, aos documentos escritos e não à análise da prática ou das demais fases do currículo.

\section{UMA TEORIA FUNDAMENTADA EM DADOS}

A finalidade da pesquisa de acordo com Gil (2010, p. 27) corresponde à busca por "novos conhecimentos direcionados a amplas áreas com vistas à solução de reconhecidos problemas práticos". A pergunta-chave adquiriu, então, a seguinte conformação: em que medida a proposta curricular de música do curso pedagogia da UnB dialoga com a proposta para o trabalho com música da etapa da educação infantil presente no Currículo em Movimento do DF?

Sob a perspectiva da teoria fundamentada nos dados (Charmaz, 2009), as análises qualitativas da pesquisa transcorreram em três fases. Na Codificação Inicial Aberta foram coletados trechos dos documentos, estes que, como unidades de análise, foram codificados e categorizados. Na segunda fase, ou Codificação Axial, os dados foram reagrupados, com vistas à criação de subcategorias e categorias mais abrangentes, observando termos e concepções - relacionados aos conhecimentos musicais - que pudessem aproximar e, assim, tornar possivel o agrupamento dos códigos encontrados. Os códigos definidos como categorias carregam em si as propostas de educação musical contidas nos documentos. 


\begin{tabular}{|c|c|c|c|c|}
\hline \multicolumn{2}{|c|}{ Codificação Inicial Aberta } & \multirow[b]{2}{*}{ Códigos } & \multicolumn{2}{|c|}{ Codificação Axial } \\
\hline Documento & $\begin{array}{l}\text { Unidade de análise: } \\
\text { Quadro Organizativo }\end{array}$ & & Subcategorias & Categorias \\
\hline $\mathrm{CM}$ & $\begin{array}{l}\text { Escuta atenta de } \\
\text { diversos sons, fontes } \\
\text { sonoras e gêneros } \\
\text { musicais (música } \\
\text { folclórica, erudita, } \\
\text { popular e popular } \\
\text { de massa). }\end{array}$ & $\begin{array}{l}\text { - Escuta } \\
\text { atenta } \\
\text { - Fontes } \\
\text { sonoras } \\
\text { diversas } \\
\text { - Gêneros } \\
\text { musicais } \\
\text { diversos }\end{array}$ & $\begin{array}{l}\text { - Apreciação } \\
\text { musical }\end{array}$ & \multirow{4}{*}{$\begin{array}{l}\text { Experiências } \\
\text { sonoro-musicais }\end{array}$} \\
\hline $\mathrm{CM}$ & $\begin{array}{l}\text { Percepção de sons } \\
\text { e ruídos: descober- } \\
\text { tas e relação a suas } \\
\text { fontes sonoras. }\end{array}$ & $\begin{array}{l}\text { - Percepção } \\
\text { de sons e } \\
\text { ruídos } \\
\text { - Fontes } \\
\text { sonoras } \\
\text { diversas }\end{array}$ & $\begin{array}{l}\text { - Percepção } \\
\text { sonora }\end{array}$ & \\
\hline $\mathrm{CM}$ & $\begin{array}{l}\text { Expressão livre e } \\
\text { direcionada por } \\
\text { meio do canto }\end{array}$ & $\begin{array}{l}\text { - Expressão } \\
\text { livre pelo } \\
\text { canto } \\
\text { - Expressão } \\
\text { direcionada } \\
\text { pelo canto }\end{array}$ & $\begin{array}{l}\text { - Expressão } \\
\text { musical }\end{array}$ & \\
\hline $\mathrm{CM}$ & $\begin{array}{l}\text { Participação em ati- } \\
\text { vidades com músi- } \\
\text { cas }\end{array}$ & $\begin{array}{l}\text { - Participação } \\
\text { em ativida- } \\
\text { des musicais } \\
\text { - Formação } \\
\text { do repertório }\end{array}$ & $\begin{array}{l}\text { - Interação } \\
\text { musical } \\
\text { - Socialização } \\
\text { - Enriqueci- } \\
\text { mento musi- } \\
\text { cal e cultural }\end{array}$ & \\
\hline
\end{tabular}

Quadro 1: Exemplo de codificação pela teoria fundamentada nos dados.

Fonte: modelo de codificação proposto pela autora com base na TFD.

Outra finalidade do processo de codificação foi a definição e estruturação conceitual de cada grupo. Os adensamentos teóricos construídos tornaram realizável um posterior exercício de comparação e estabelecimento de relações com categorias emergentes da codificação de outros documentos. A terceira ${ }^{a}$ fase do processo, chamada Codificação Seletiva, conduz a essa integração teórica, onde, após identificar os conceitos, o texto é escrito de maneira analítica e detalhada até que a teoria acerca do fenômeno desponte, fundamentada nos próprios dados e apoiada por outras teorias.

Nessa fase, é como se as teorias recebessem legendas sobre as suas especificidades. O texto passa, então, a uma estrutura temática, o que possibilita 
a identificação de uma categoria central que revela a principal concepção de educação musical contida nos documentos. Nas palavras de Gil (2010, p. 148) essa categoria "emerge ao final da análise e constitui o tema central ao redor da qual giram todas as outras categorias. Consiste de todos os produtos de análise, condensados em poucas palavras capazes de explicar sobre o que é a pesquisa."

Todo o processo de análise descrito ocorreu individualmente em cada documento. Primeiro no caderno da educação infantil do Currículo em Movimento $^{2}$ e, complementar a ele, no caderno de pressupostos teóricos desse currículo; depois no Projeto Acadêmico do Curso de Pedagogia (PACP) da UnB (Universidade de Brasília, 2002), bem como nas ementas de disciplinas relacionadas a conhecimentos musicais e artísticos (Universidade de Brasília, 2018). Esses outros documentos foram selecionados para a pesquisa tendo em vista a necessidade de verificar de forma efetiva e significativa a concepção teórico-prática de educação musical, disposta nos documentos.

\section{A MÚSICA E SEUS ESPAÇOS NA EDUCAÇÃO INFANTIL...}

As análises revelaram a concepção de educação musical em cada documento. No Currículo em Movimento, os conteúdos são abordados como linguagens, "é uma tentativa de não fragmentar os conhecimentos e de considerar a multidimensionalidade das crianças, ainda que seja necessário indicar parâmetros para o trabalho educativo a ser desenvolvido" (Distrito Federal, 2014 , p. 85). A música integra a linguagem artística, junto às artes visuais e às artes cênicas / teatro. ${ }^{3}$

Embora cada campo de linguagem possua o próprio espaço no documento para o debate de suas especificidades, o texto reforça a intencionalidade de que o trabalho seja realizado de forma integrada e interdisciplinar e tenha como princípios orientadores a harmonização entre a teoria e a prática.

Para a codificação, foram retirados do texto trechos que apontavam relação com conhecimentos e atividades musicais. As primeiras unidades de análise foram retiradas do quadro organizativo da música, depois dos demais trechos de todo o caderno da educação infantil, e por fim, do caderno de pressupostos teóricos. A ideia foi partir das especificidades e concepções relativas aos conhecimentos musicais, para então analisar a distribuição da música em espaços interdisciplinares bem como enquanto componente elementar da proposta de formação integral da criança.

\footnotetext{
2 Em sua primeira versão, o Currículo em Movimento do Distrito Federal conta com oito cadernos, cada qual destinado a uma fase da educação. Foram selecionados para a pesquisa o caderno de pressupostos teóricos e o caderno da educação infantil.

3 A primeira edição do Currículo Movimento é anterior à lei no 13.278 de 2016, que alterou a redação dada para o 6o parágrafo do artigo 26 pela lei no 3.394/1996 (Brasil, 1996), passando a vigorar com o seguinte texto: "As artes visuais, a dança, a música e o teatro são as linguagens que constituirão o componente curricular de que trata o § 2ㅇ deste artigo" (Brasil, 2016).
} 
Com base nas análises, foi possivel estimar que uma grande categoria endossa o que o Currículo em Movimento concebe sobre a linguagem musical, sendo esta nomeada de "experiências sonoro-musicais", é este o termo que define como os conhecimentos devem ser trabalhados na educação infantil. As demais categorias ilustradas na figura abaixo definem características funcionais da música, trazendo aspectos específicos "do som e da música", funções "do professor, da escola" e como funcionará a "avaliação" nesse trabalho, e pontos em que a música contribuirá com o processo de formação humana das crianças. Todas essas categorias são envolvidas pela concepção de uma educação musical ampla.

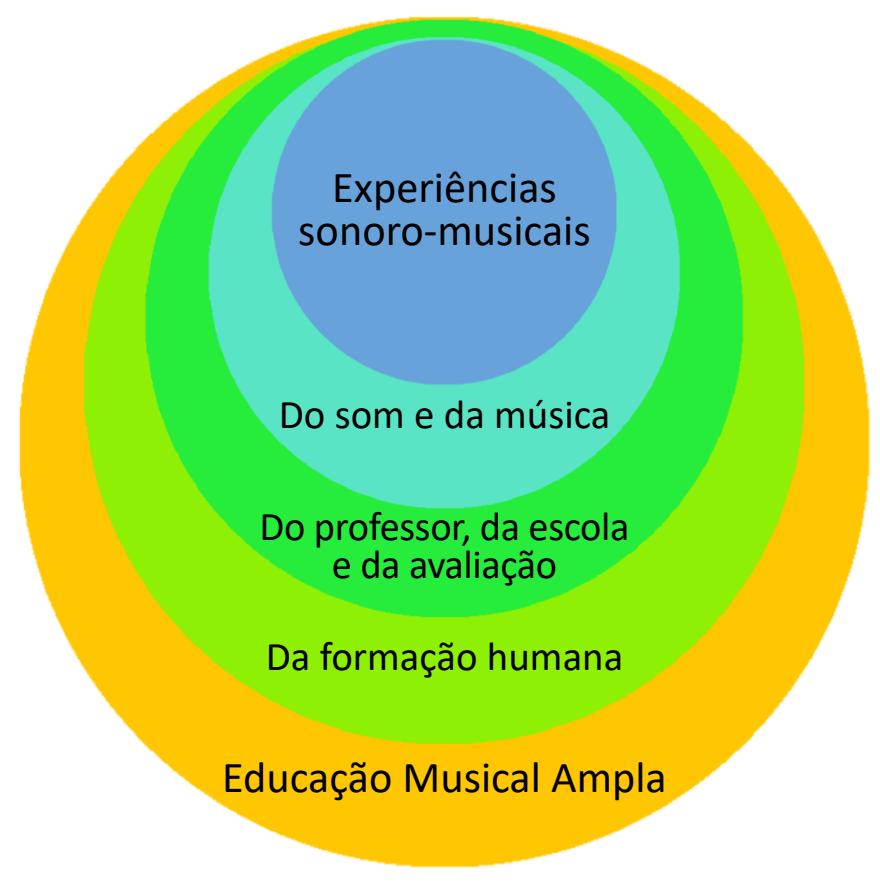

Diagrama 1: A educação musical no Currículo em Movimento. Fonte: elaborado pela autora com base nas análises do CM da EI.

A categoria central, denominada Experiências sonoro-musicais, abriga todas as categorias referentes aos conteúdos, metodologias, atividades, focos de desenvolvimento e contextos expressados no documento. São vivências com a música onde os "conteúdos" musicais serão experienciados, o que está de acordo com o nível de desenvolvimento cognitivo (e musical, segundo o próprio Swanwick) da criança que está na educação infantil. As metodologias foram divididas em Criação, Apreciação e Execução, modalidades centrais do fazer musical, ou seja, atividades que nos envolvem diretamente com a música. A partir dessas modalidades, as categorias foram organizadas, evidenciando os conhecimentos musicais e o "como" desenvolver esses conhecimentos, no Diagrama 2. 


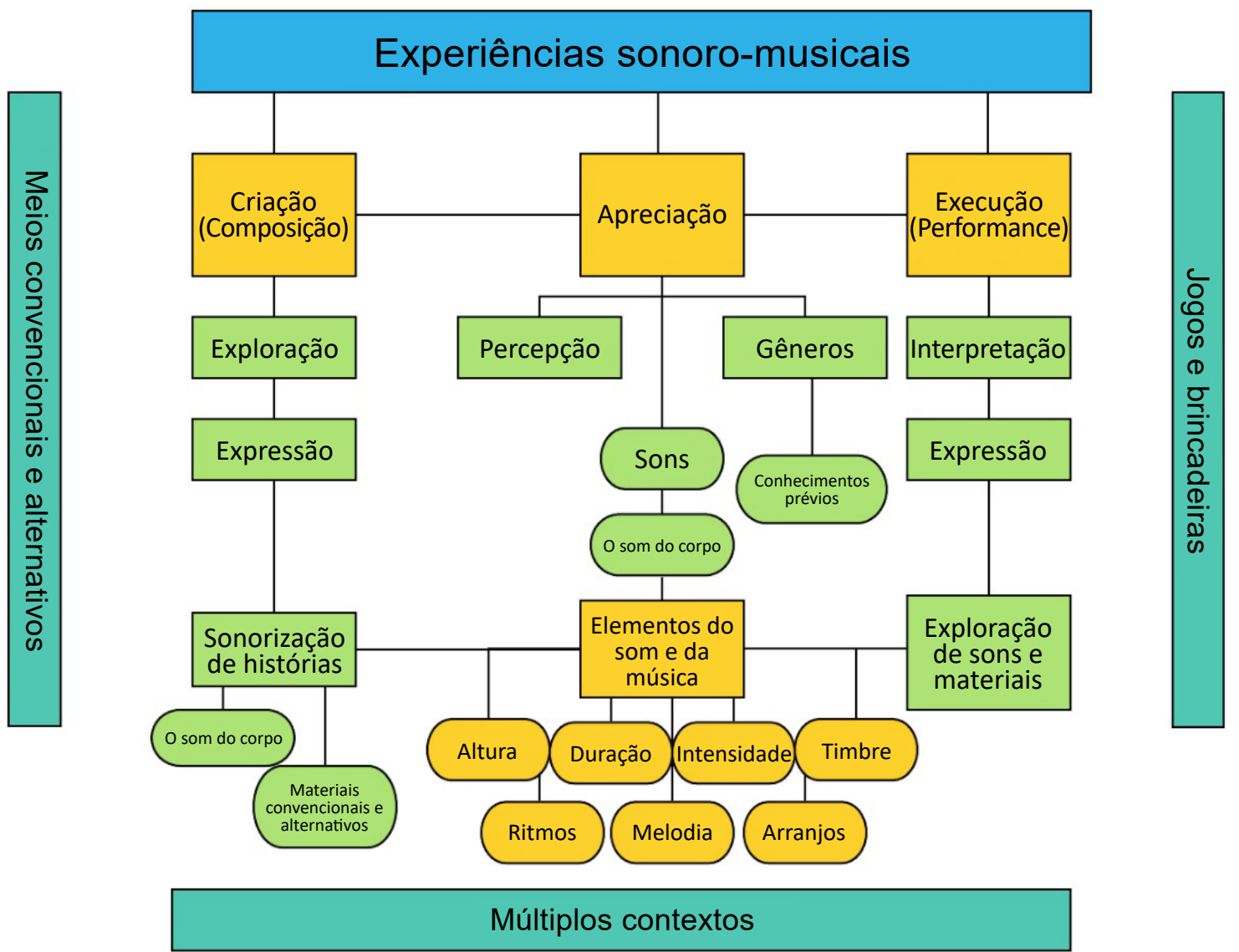

Diagrama 2: Experiências sonoro-musicais no Currículo em Movimento. Fonte: organizado pela autora com base nas análises do CM da EI.

Os códigos que emergiram do documento permitiram o diálogo com as propostas de Keith Swanwick no que se refere às modalidades do fazer musical: Composição (C), Apreciação (A) e Performance (P). No Currículo em Movimento, outros termos são utilizados para nomear essas modalidades: "criação", em vez de "composição"; e "execução" no lugar de "performance". Apesar de adaptada, a nomenclatura não modifica o sentido dos termos.

França e Swanwick $(2002$, p. 8) consideram essas modalidades como processos fundamentais de uma educação musical abrangente, pois constituem "possibilidades fundamentais de envolvimento direto com a música [...] conduzindo a insights particulares em relação ao funcionamento das ideias musicais". Em outras palavras, uma educação musical abrangente se dedica ao desenvolvimento musical dos alunos por meio do engajamento com a música, em "experiências acessiveis e musicalmente ricas e variadas" (França; Swanwick, 2002, p. 8), o que equilibra a execução em relação às modalidades de criação e apreciação.

É preciso destacar essa fala pelo fato de ser comum que as escolas privilegiem a execução de canções em ensaios repetitivos e pouco criativos com a única finalidade de "enfeitarem" as festividades escolares com apresentações 
musicais. A criação (ou composição) é significativamente considerada para o desenvolvimento musical, pois:

qualquer que seja o nivel de complexidade, estilo ou contexto, é o processo pelo qual toda e qualquer obra musical é gerada. Esse argumento é suficiente para legitimá-la como atividade válida e relevante na educação musical (França; Swanwick, 2002, p. 8).

A proposta de educação musical ampla apresentada pelo Currículo em Movimento integra as especificidades da música e as especificidades da educação infantil, ou seja: como os múltiplos contextos dialogam e interferem nas questões musicais e vice-versa. Da mesma forma, por quais meios convencionais e alternativos as experiências sonoro-musicais podem ser contempladas, incluindo os jogos e brincadeiras que são intrínsecos a essa etapa da educação.

As ações de criação, apreciação e execução musicais requerem conhecimentos específicos para que sejam trabalhadas com qualidade e de maneira adequada. Portanto, observar os espaços da música na formação de pedagogos faz-se necessário. Nesse sentido, os próximos parágrafos trazem alguns resultados da codificação da proposta de música do curso de Pedagogia da UnB.

\section{... E NA FORMAÇÃO DE PEDAGOGOS}

As unidades de análise extraídas do Projeto Acadêmico do Curso de Pedagogia evidenciam a base de formação proposta pela Faculdade de Educação da UnB, ou seja, trazem as características profissionais pretendidas aos licenciados. Para a escolha das unidades de análise foram definidos alguns pontos:

- Concepção de formação de pedagogos do curso e possivieis influências da proposta curricular ao alcance dessa concepção.

- Proposta de interação com as demais disciplinas.

- Potenciais repercussões das concepções teórico-metodológicas, definidas para o curso, na prática pedagógica dos pedagogos licenciados.

Para conduzir, inicialmente, a análise do projeto pedagógico do curso de Pedagogia, foi eleita a seguinte questão norteadora: como é concebida a base docente na formação do pedagogo?

Como resultantes da análise do texto do PACP da UnB, obteve-se a categoria central de uma atuação profissional plena, onde por meio da própria e constante reflexão sobre a prática pedagógica o pedagogo possa conceber o ser humano como centro do processo educativo, praticando a integração entre teoria e prática. 


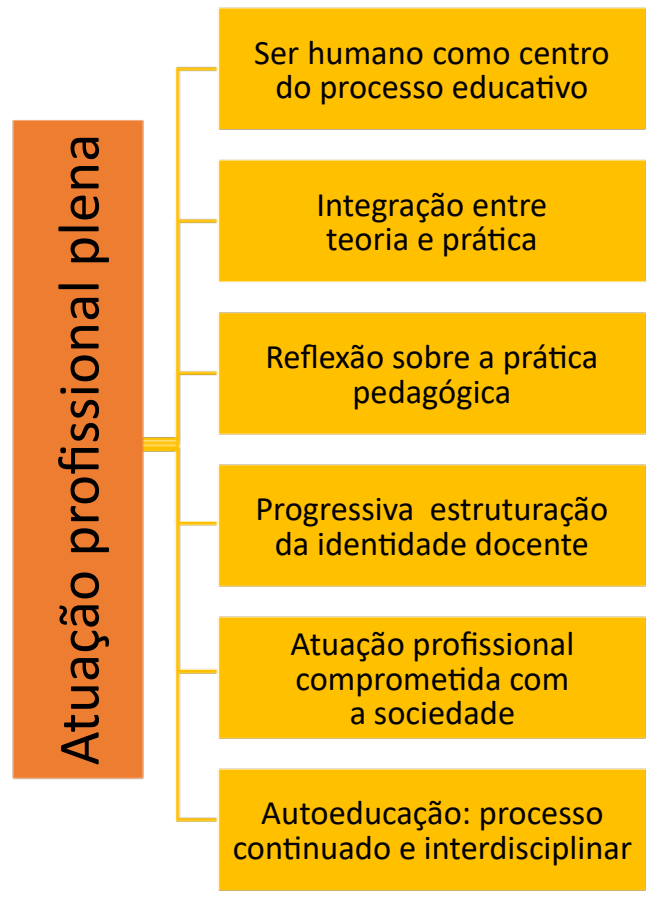

Diagrama 3: Base de formação docente do PACP da UnB.

Fonte: organizado pela autora com base nas análises do PACP da UnB.

O pedagogo então, consciente de sua progressiva estruturação da identidade docente, passa a entender a importância de assumir a responsabilidade por sua autoeducação como necessário processo continuado e interdisciplinar, em ações e reflexões que oportunizam uma atuação profissional comprometida com a sociedade (cf. Diagrama 3).

Após a leitura do texto do PACP passou-se às especificidades do ensino de música e artes, dispostos em disciplinas específicas. Para a análise foram selecionadas todas as disciplinas relacionadas ao ensino da linguagem musical ou da linguagem artística, disponiveis aos alunos do curso de Pedagogia no fluxo curricular optativo, tendo em vista a não existência de disciplinas de arte ou música em fluxo curricular obrigatório.

As disciplinas selecionadas para a análise foram:

- Fundamentos da Arte na Educação;

- Fundamentos da Linguagem Musical na Educação;

- Canto Coral 1, 2 e 3;

- Arte, Pedagogia e Cultura;

- Oficina Básica de Música.

Do processo de codificação das unidades de análise extraídas das ementas disciplinares, emergiram categorias que revelaram a proposta para o ensino de música que compõem a base de formação dos pedagogos. Entretanto, é preciso lembrar que cursar a disciplina está no âmbito de livre escolha do futuro professor, o que torna possivel ou não o contato com os conteúdos e 
possivel aquisição dos conhecimentos e experiências musicais propostos nas ementas analisadas.

O Diagrama 4 retrata uma síntese dos resultados do processo de análise das ementas disciplinares. A categoria denominada Educação musical por meio de experiências sonoro-musicais foi posta como central pela recorrência dos termos no processo de categorização, e representa a proposta para o ensino de música presente no currículo de Pedagogia da UnB - sendo por coincidência, ou não, homônimo ao termo central da análise do documento anterior.

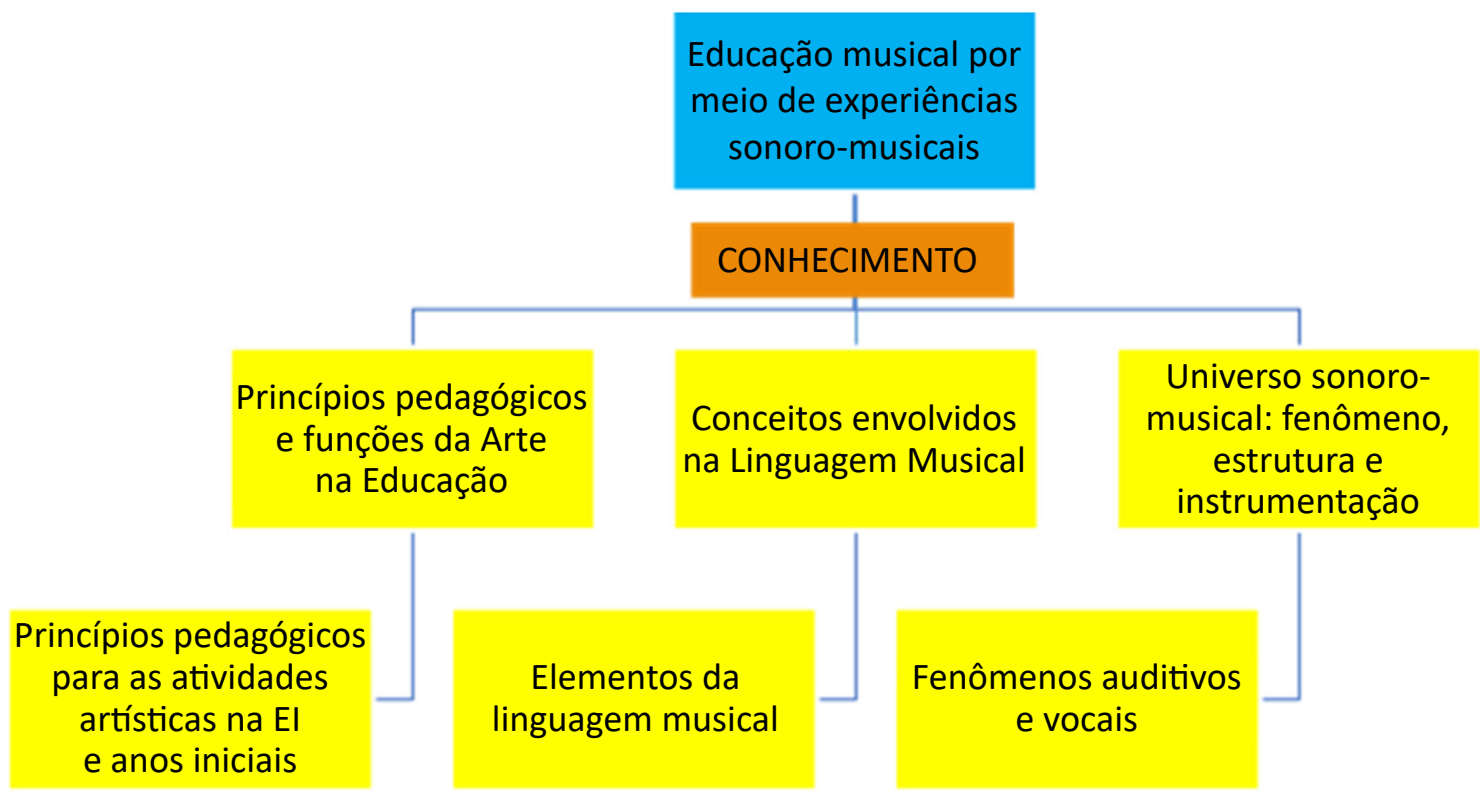

Diagrama 4: Educação musical na formação de pedagogos do PACP da UnB. Fonte: elaborado pela autora com base nas codificações do PACP da UnB.

Cada código posto na organização do Diagrama 4 representa, além dos conteúdos musicais, as especificidades do ensino da arte aos licenciandos do curso, e cada código foi extraído do processo de codificação de uma disciplina; com exceção dos "Conceitos envolvidos na Linguagem Musical" e "Elementos da linguagem musical", que resultaram da análise da disciplina de Fundamentos da Linguagem Musical na Educação (FLME).

O Diagrama 4 foi organizado de maneira que os códigos representem o aprofundamento dos conhecimentos na segunda fileira. Como exposto, os conhecimentos dos "Princípios pedagógicos e funções da Arte na Educação" passam a possuir um direcionamento com vistas ao ensino dos "Princípios pedagógicos para as atividades artísticas na EI e anos iniciais". Padrão que se repete nas demais colunas do diagrama. 
No centro do diagrama, os "Conceitos envolvidos na Linguagem Musical" e os "Elementos da linguagem musical" são códigos centrais extraídos da disciplina de FLME, como afirmado anteriormente, que é a única disciplina de onde emergiu tanto o código central quanto a possibilidade de aprofundamento nos conhecimentos musicais. A disciplina Oficina Básica de Música também cumpre esse papel, entretanto, a possibilidade de que os alunos cursem a disciplina de FLME é maior, pelo fato de que esta é oferecida pela Faculdade de Educação, enquanto que a Oficina Básica de Música é ofertada pelo Departamento de Música, em outra unidade da UnB. Durante o processo de codificação foi possivel perceber a disciplina de FLME como um proveitoso caminho de formação musical inicial para os licenciandos em Pedagogia da UnB.

Em resumo, o lado esquerdo do diagrama apresenta conhecimentos pedagógicos gerais acerca do ensino das artes, que são inerentes ao curso pela temática deste, que é a pedagogia. No centro do Diagrama 4, os códigos revelam especificidades sobre o ensino de música na educação, tratando de conceitos gerais; e, no lado direito do diagrama, disciplinas que apresentam um aprofundamento do ensino de música no curso, oferecidas, inclusive, pelo Departamento de Música da UnB.

Esse processo de codificação exibe uma realidade otimista e ao mesmo tempo preocupante. Otimista ao revelar que a proposta para o ensino de música no curso de Pedagogia da UnB apresenta potencialidades de oferecer conhecimentos musicais relacionados com o que é exigido na parte de música do currículo para a educação infantil do DF. Preocupante pelo fato de que as cinco disciplinas estão em fluxo optativo, não garantindo a todos a formação básica necessária para atuar com essa área de conhecimento obrigatória por lei em sua prática docente futura.

Outra preocupação está nas relações entre a formação musical do pedagogo e a prática pedagógica. Em outras palavras, para além das oportunidades às vivências e experiências sonoro-musicais em disciplinas obrigatórias, podem existir questões nos entremeios até a efetivação dessas atividades, como os espaços físicos das instituições, os materiais apresentados aos professores e alunos, os projetos político-pedagógicos, recursos destinados a esses espaços e projetos de formação continuada, em educação musical, para os docentes.

Devo relembrar que a presente pesquisa se mantém ao nível das prescrições curriculares, sendo importante elucidar não ser essa uma garantia de que as experiências sonoro-musicais estejam presentes nas salas de aula da educação infantil e anos iniciais. Entretanto, também é importante considerar que o currículo prescrito carrega em si uma significação social e, por isso, "aspectos que atuam como referência na ordenação do sistema curricular servem de ponto de partida para a elaboração de materiais, controle do sistema, etc" (Gimeno Sacristán, 2017, p. 103). O currículo, de acordo com Gimeno Sacristán (2017), tem um processo de desenvolvimento organizado em fases, e cada uma dessas fases pode representar mudanças no caminho que se segue da prescrição ao currículo realizado (prática). 


\section{O CONHECIMENTO PEDAGÓGICO DO CONTEÚDO}

A fim de correlacionar as categorias emergentes dos dois processos de codificação, foi encontrado na teoria do conhecimento pedagógico do conteúdo, de Shulman (2014), um ponto de confluência neutro, capaz de abrigar os códigos e categorias e possibilitar as ações de organização dos diferentes conhecimentos propostos nos currículos e a posterior comparação destes.

Shulman (2014, p. 206) estrutura o conhecimento do professor em categorias; o autor acredita que se esse conhecimento fosse disposto em um manual, as categorias poderiam ser organizadas da seguinte forma:

- conhecimento do conteúdo;

- conhecimento pedagógico geral com especial referência aos princípios e estratégias mais abrangentes de gerenciamento e organização de sala de aula, que parecem transcender a matéria;

- conhecimento do currículo, particularmente dos materiais e programas que servem como "ferramentas do ofício" para os professores;

- conhecimento pedagógico do conteúdo, esse amálgama especial de conteúdo e pedagogia que é o terreno exclusivo dos professores, seu meio especial de compreensão profissional;

- conhecimento dos alunos e de suas características;

- conhecimento de contextos educacionais, desde o funcionamento do grupo ou da sala de aula, passando pela gestão e financiamento dos sistemas educacionais, até as características das comunidades e suas culturas; e

- conhecimento dos fins, propósitos e valores da educação e de sua base histórica e filosófica.

O "conhecimento do currículo" é considerado por Shulman como um ponto crucial para a formação e o desenvolvimento da prática docente, por ser como um tipo de "ferramenta do ofício". É certo que esse conhecimento não é garantia de que os conteúdos sejam trabalhados ao mesmo nivel e nem com os mesmos métodos, entretanto, é um elemento-chave para a difusão dos conhecimentos por conter "o que" deve ser ensinado, e o "como".

É de suma importância que o professor busque conhecer o referencial que orienta a construção curricular em seu país, estado/distrito, município, bem como se coloque à disposição de participar da construção desses documentos. Essas prescrições curriculares representam, por vezes, possibilidades de realização desse currículo diante das especificidades socioculturais das comunidades.

O "conhecimento dos alunos e de suas características", "conhecimento de contextos educacionais" e "conhecimento dos fins, propósitos e valores da educação e de sua base histórica e filosófica" podem ser diretamente relacionados com os princípios éticos, políticos e estéticos apontados pelo CM como princípios de base ao trabalho pedagógico com a educação infantil. A base de formação docente do PACP apresenta também códigos de relação direta com a referência citada, são eles o "Ser humano como centro do processo educativo", 
a "Atuação profissional comprometida com a sociedade", a "Autoeducação [como] processo continuado e interdisciplinar" (cf. Diagrama 3).

Intencionalmente deixados por último, o "conhecimento do conteúdo", o "conhecimento pedagógico" e o "conhecimento pedagógico do conteúdo" fornecem os recursos necessários para o processo de correlação entre os dois documentos. Essas são as três categorias, entre as demais apresentadas pelo autor, selecionadas como ferramentas de organização das categorias emergentes dos processos de codificação.

O "conhecimento do conteúdo" trata do conteúdo específico, que no caso da presente pesquisa representa os elementos do som e da música: "Altura", "Duração", "Intensidade", "Timbre", "Ritmo", "Melodia" e "Arranjos", códigos extraídos do Currículo em Movimento. Da codificação das ementas do PACP, os conteúdos são: "Conceitos envolvidos na Linguagem Musical", "Elementos da linguagem musical", "Universo sonoro-musical: fenômeno, estrutura e instrumentação" e "Fenômenos auditivos e vocais".

O "conhecimento pedagógico geral" está presente em caráter teórico e prático nas diversas disciplinas e etapas de um curso de pedagogia, a fim de que seus fundamentos possam fundamentar a vivência dos estágios, projetos de prática e em especial no decorrer da prática docente. No caso desta pesquisa, refere-se aos seguintes códigos extraídos do PACP: "Integração entre teoria e prática", "Reflexão sobre a prática pedagógica" e "Progressiva estruturação da identidade docente". Nas análises das ementas disciplinares relacionadas à música (e à área de arte) emergiram dois códigos que também se relacionam diretamente ao "conhecimento pedagógico geral", são eles "Princípios pedagógicos e funções da Arte na Educação" e "Princípios pedagógicos para as atividades artísticas na EI e anos iniciais". Tudo isso contribuindo para uma "Atuação profissional plena" - categoria central dessa codificação e da concepção apresentada pela UnB para a formação de pedagogos (cf. Diagramas 3 e 4).

O CM da educação infantil também apresenta especificidades da organização do trabalho pedagógico como materiais, ambientes e tempos, além das orientações e recomendações em relação às práticas sociais antes mesmo de explicitar sua organização curricular que divide os conhecimentos em linguagens. Ainda que o currículo considere o pedagogo como um especialista da infância, listar todos esses aspectos de prática e vivência com a educação infantil reforça os princípios de conhecimento pedagógico geral adquiridos durante a licenciatura em pedagogia, como também - e principalmente - os princípios que orientam o trabalho no Distrito Federal à luz das diretrizes nacionais. Portanto, não se trata apenas de um documento de organização do trabalho pedagógico, mas de toda uma estrutura pensada para as diversas realidades e contextos escolares e familiares encontrados no DF.

Com fundamento nessa observação, e percebendo o entrelaçamento de conhecimentos e metodologias trazido pelo currículo, chegou-se ao nivel do "conhecimento pedagógico do conteúdo" (PCK), ${ }^{4}$ que Shulman apresenta como

\footnotetext{
4 Conhecimento pedagógico do conteúdo ou PCK, da sigla em inglês "Pedagogic Content Knowledge".
} 
o "amálgama" entre o pedagógico e o conteúdo. É o ponto de confluência entre "o que" o professor precisa saber e o "como" deve ensiná-lo, como dito anteriormente. Se observarmos o Diagrama 4 poderemos associar ao PCK o modo como os conhecimentos musicais são propostos, por meio de experiências sonoro-musicais de criação, apreciação e performance.

Quando as ementas do PACP analisadas descrevem atividades que devem ser vivenciadas pelos licenciandos, também por meio de experiências sonoro-musicais - categoria central de mesmo nome da categoria central do Currículo em Movimento -, estão a sugerir que eles possam aprender sobre o conteúdo a partir dessas experiências para que, paralelamente, compreendam maneiras de promover os conhecimentos, vivências e experiências musicais em suas futuras práticas pedagógicas.

O Diagrama 5, abaixo, representa a teoria de Shulman, PCK, configurada em diálogo com as análises desta pesquisa, flexibilizada a exemplo da pesquisa de Fernandez (2011) que traz alguns modelos de PCK propostos na literatura. Na ocasião, a autora defende que o estudo do PCK pode auxiliar licenciandos em seu processo de formação, bem como professores mais experientes. Essa é uma das finalidades da captação das diversas formas atribuídas à teoria: "Explicitar sua importância em termos de linha de pesquisa para compreender o desenvolvimento profissional docente" (Fernandez, 2011, p. 11).

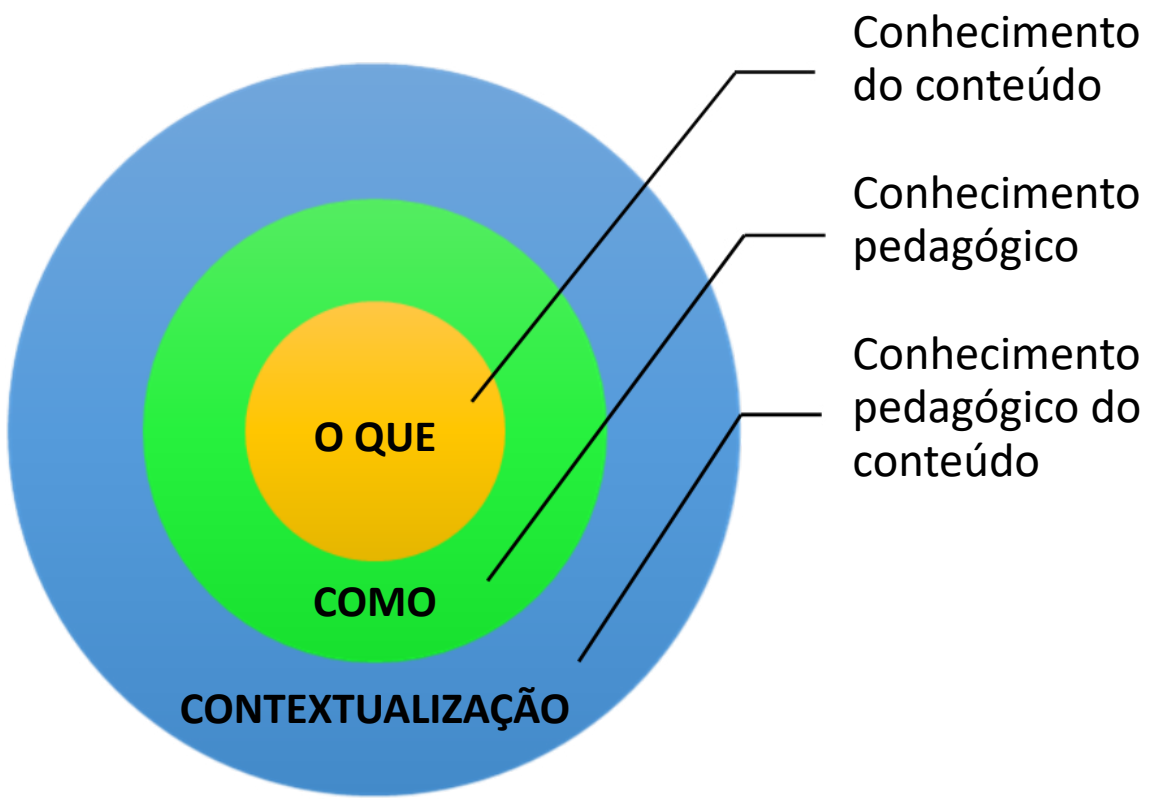

Diagrama 5: Conhecimento pedagógico do conteúdo de música. Fonte: elaborado pela autora com base na teoria PCK de Shulman (2014). 
Após realizadas essas análises, é preciso retomar a questão de pesquisa que norteou toda a investigação: como os conhecimentos musicais da proposta curricular do curso de Pedagogia da UnB se correlacionam com a proposta para o trabalho com música da etapa da educação infantil no Currículo em Movimento do DF?

Abaixo seguem as estruturas que retratam essas relações. Do lado esquerdo os códigos da formação de pedagogos e em paralelo os do Currículo em Movimento. Partindo do pressuposto de uma ordem de acontecimentos, em que primeiro o pedagogo recebe uma formação para então conceber o currículo da educação básica como guia.

- O conhecimento do conteúdo de música está localizado nos dois currículos. Nas ementas disciplinares do PACP encontramos uma estrutura de conhecimentos específicos da música que subsidiam os encontrados no Currículo em Movimento.

\section{Ementas disciplinares do PACP}

Conceitos envolvidos na linguagem musical

Elementos da linguagem musical

Universo sonoro-musical

Fenômenos auditivos e vocais

\section{Curriculo em Movimento}

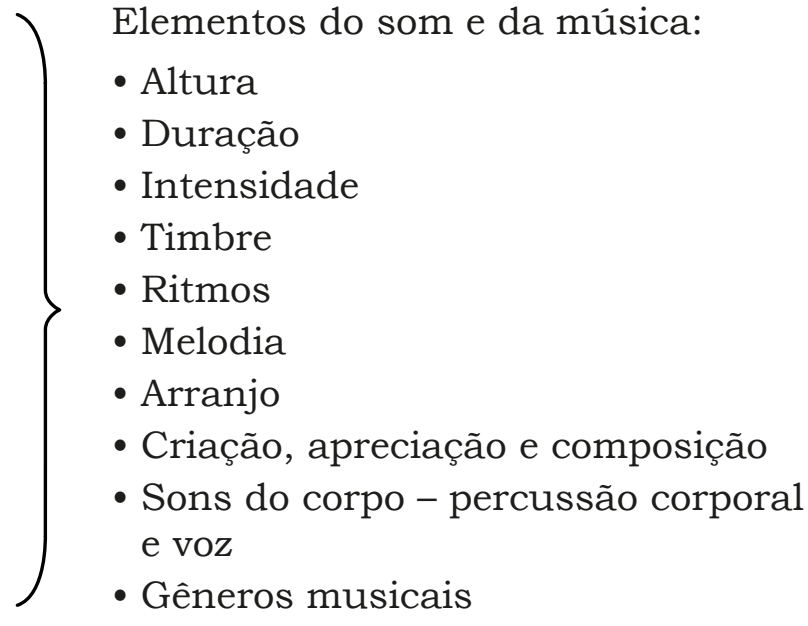

As modalidades centrais e diretas do fazer musical - criação, apreciação e execução, por se constituírem como habilidades específicas da experiência musical, podem ser compreendidas também como um "conteúdo" a ser aprendido e dominado, principalmente porque, como se verá adiante, se tornarão também um "como", um meio de trabalhar outros conhecimentos musicais.

- O conhecimento pedagógico, que são os fundamentos da pedagogia ou a maneira "como" os conhecimentos são desenvolvidos e vivenciados. Trata de toda a organização didática proposta pelos currículos. Por se tratar de um curso de pedagogia, o curso da UnB traz esses indícios em todo o projeto, nos aspectos pedagógicos, políticos e estruturais, o que se reflete também nas estruturas das disciplinas. 
São características que, apesar de não serem diretamente relacionadas com a música, constituem fatores que intervêm a favor do processo de ensino-aprendizagem de todos os conhecimentos e vivências explicitadas nesses currículos. Um exemplo: a categoria de "Integração entre teoria e prática" do PACP é um fator que representa, dentre outros, a promoção de ações nas disciplinas de música que integram, como o próprio nome diz, os conhecimentos teóricos aos práticos, categoria que pode ser diretamente relacionada à concepção pedagógica do $\mathrm{CM}$ para o trabalho com música que é realizado através de experiências sonoro-musicais, ou seja, em atividades promovidas pelo professor que integrem os conhecimentos adquiridos em sua formação e os conhecimentos direcionados às crianças de forma prática.

A concepção da base docente do PACP manifesta os pilares do conhecimento pedagógico no curso, tendo como categoria central a "Atuação profissional plena"; da mesma forma, existe uma concepção de "Educação Musical Ampla" no Currículo em Movimento. O que interliga as bases dos dois documentos curriculares é que a "atuação plena" proposta na formação dos pedagogos possibilita o entendimento e o autorreconhecimento desses profissionais como os sujeitos mais próximos da realização do currículo escolar, e, portanto, da educação musical por uma perspectiva ampla, como proposto no Currículo em Movimento.

\section{Base docente do PACP: Atuação profissional plena}

Ser humano como centro do processo educativo

Integração entre teoria e prática

Reflexão sobre a prática pedagógica

Progressiva estruturação da identidade docente

Atuação profissional comprometida com a sociedade

Autoeducação: processo continuado e interdisciplinar

\section{Curriculo em Movimento: Educação Musical Ampla}

- Especificidades do professor, da escola e da avaliação no processo de ensino-aprendizagem

- Reconhecimento da música como elemento essencial para a formação humana

- O conhecimento pedagógico do conteúdo, que é como um amálgama dos dois anteriores, é representado por categorias de nomes análogos, resultantes da codificação dos dois documentos. 


\section{Ementas disciplinares do PACP}

Educação musical por meio de experiências sonoro-musicais

\section{Curriculo em Movimento}

- Experiências sonoro-musicais (orientações para o trabalho com os conhecimentos musicais na educação infantil de criação, apreciação e execução mediante atividades de experiências sonoro-musicais em múltiplos contextos, com meios convencionais e alternativos e jogos e brincadeiras.)

Apesar de análogas, as categorias representam aplicabilidades distintas, por conta das fases (idades dos professores e alunos) e intencionalidades (formar professores ou o desenvolvimento de crianças). Na formação de professores, as experiências sonoro-musicais intencionam o trabalho de conscientização, compreensão e desenvolvimento da musicalidade dos seus profissionais. Atividades que unem o conhecimento teórico em música integradas a experiências intencionalmente planejadas para integrarem mais tarde a organização do trabalho pedagógico do futuro professor.

Abaixo, o conhecimento pedagógico do conteúdo das artes em geral. A coluna da esquerda apresenta, de uma forma geral, os princípios pedagógicos para o trabalho com arte proposto pelo PACP e a coluna da direita, a base para o trabalho com arte, com foco nos conhecimentos musicais, proposto pelo CM.

\section{Ementas disciplinares do PACP}

Princípios pedagógicos e funções da Arte na educação

Princípios pedagógicos para as atividades artísticas na EI e anos iniciais

\section{Curriculo em Movimento}

- Aprendizagem por intervenção de meios convencionais e alternativos

- Aprendizagem em/ relacionadas a/ considerando múltiplos contextos.

- Metodologias de ensino por meio de jogos e brincadeiras.

- Princípios éticos, politicos e estéticos base da orientação para o trabalho com a educação infantil.

O Currículo em Movimento legitima a experiência como campo pelo qual os conhecimentos são desenvolvidos no processo de aprendizagem. Sendo assim, o conhecimento musical fará sentido progressivamente, conforme as experiências sonoro-musicais sejam desenvolvidas, sem que o foco seja o repasse de conceitos e da teoria formal.

O resgate ou desenvolvimento da própria musicalidade representa a principal relação entre os dois currículos, nos quais o conhecimento pedagógico do conteúdo de música faz-se presente via experiências sonoro-musicais, oferecendo assim subsidios aos futuros professores para o trabalho com música proposto no Currículo em Movimento da educação infantil do DF. 


\section{RELAÇÕES ENTRE AS PRESCRIÇÕES CURRICULARES}

Em seu contexto mais amplo, que transcende o recorte apresentado neste artigo, a pesquisa propôs uma triangulação curricular que tem a relação entre os dois currículos como sua base:

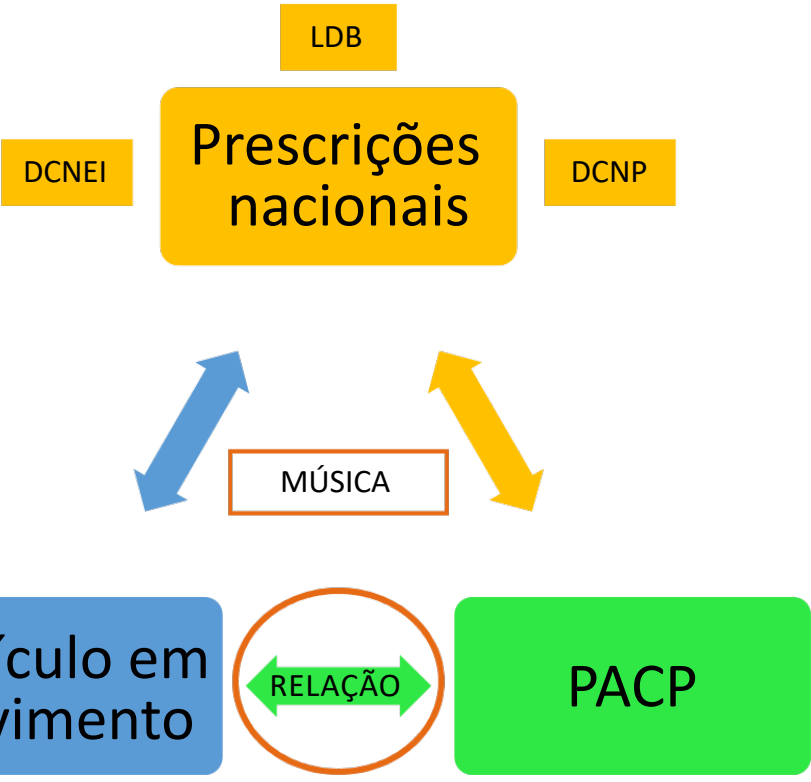

\footnotetext{
Diagrama 6: Triangulação das prescrições curriculares - relação CM e PACP. Fonte: elaborado pela autora com base nos documentos curriculares nacionais e a proposta da pesquisa.
}

Retomando a pergunta inicial, e em vista dos argumentos apresentados, é possivel afirmar que existe uma potencial relação entre o caderno de educação infantil do Currículo em Movimento e o Projeto Acadêmico do Curso de Pedagogia da UnB no que se refere aos conhecimentos musicais.

Em outras palavras, o PACP da UnB oferece potencialmente aos seus licenciandos as bases para um futuro trabalho com música na educação infantil. Diz-se potencialmente porque, todavia, todas as disciplinas analisadas que se referem à música integram o fluxo do curso em caráter optativo, o que possibilita, mas não garante, o contato dos alunos com os conhecimentos musicais.

Outra reflexão pertinente a esse debate refere-se à carga horária que os licenciandos teriam ao final do curso. Ainda que as três disciplinas específicas de música aqui citadas (Linguagem Musical na Educação, Oficina Básica de Música e Canto Coral) fossem escolhidas como disciplinas optativas, sua carga horária somaria, aproximadamente, 180 horas/aula, das 3.200 horas totais do curso, o que representa um contato mínimo com experiências sonoro-musicais, na proposta curricular, que poderá ser aprofundado ao longo da formação continuada. 
Ainda que minimo, esse contato representa um conhecimento essencial para o trabalho com a música na educação básica, além da reflexão acerca de sua importância no que se refere ao desenvolvimento das crianças, o que é indispensável. Considerando o fato de as disciplinas não serem obrigatórias, é possivel que nem esse mínimo seja efetivado. O aprender sobre a música não deveria ser optativo na formação dos professores, quando legalmente existe uma obrigatoriedade na sua prática profissional. Bellochio, Weber e Souza (2017, p. 211) colaboram com essa reflexão quando afirmam que

a formação musical durante a graduação não garante que a Música esteja presente nas práticas pedagógicas [...] porém proporciona a esses professores o contato com os conhecimentos próprios da área, mostra possibilidades de trabalho pedagógico-musical e problematiza a unidocência e suas relações com a Música na escola [...] o fato do professor unidocente vivenciar essas disciplinas, durante a graduação, pode motivá-lo a aprofundar conhecimentos musicais e pedagógico-musicais após o ensino superior.

É oportuno ressaltar que no DF a Secretaria de Educação disponibiliza aos seus profissionais alguns cursos ${ }^{5}$ por meio da Subsecretaria de Formação Continuada dos Profissionais da Educação (EAPE), bem como por meio de instituições conveniadas e parceiras. Além disso, podem-se destacar alguns projetos pontuais de extensão destinados a estudantes de licenciatura realizados na Faculdade de Educação da UnB. Portanto, existe a possibilidade de uma formação continuada que permita o aprofundamento em determinadas áreas de interesse do professor.

\section{NOTAS FINAIS}

O termo "Currículo em Movimento" vem carregado de reflexões acerca de sua significância. Para o próprio documento, o nome traz a intencionalidade de manter as orientações em movimento, em especial no que se refere aos conteúdos e direcionamentos etários. Para mim, levanta questões acerca do movimento dialético de conhecimentos essenciais aos pedagogos em sua formação e em sua prática, considerando seu posto de agente mais próximo da realização do currículo. Não há como ignorar que os conhecimentos, vivências e experiências sonoro-musicais devam ser oportunizados aos professores, ainda em sua formação, para que seja possivel oferecê-las com consistência aos seus alunos no decorrer de sua prática pedagógica.

\footnotetext{
5 Cursos disponibilizados em 2014 pela EAPE: Linguagem Musical na Educação Infantil e Anos Iniciais; Vivências com a Musicalização. Cursos disponibilizados em 2018 pela EAPE: Vivências com a Musicalização; realizado pelas Oficinas Pedagógicas: Rodas de Brincar II - Músicas, Danças, Folguedos e Brincadeiras do Brasil e do Mundo. Curso disponibilizado em 2019 e 2020: Musicalidade em Ação, Saberes e Vivências.
} 
O currículo prescrito é o primeiro lugar de observação dos conhecimentos musicais, e sua importância é evidente, ainda que haja um caminho longo até a realização de um currículo com música nas escolas de educação básica. Caminho que envolve, por exemplo, a formação continuada dos professores e a constante reflexão e convencimento dos pares acerca da importância do trabalho com música para a formação humana.

Esta pesquisa aponta que o que é exigido aos pedagogos em termos de música está assegurado pela proposta oferecida pela UnB. Assim como a adequação metodológica dessa proposta ao nivel de desenvolvimento cognitivo das crianças. O que se espera como conhecimento pedagógico do conteúdo de música também se faz presente, seja em disciplinas próprias da Faculdade de Educação ou em disciplinas do Departamento de Música da UnB. O único - e importante - senão é que essas disciplinas têm tantas chances de serem cursadas pelos futuros pedagogos quantas de não o serem.

Em outras palavras, em termos de prescrição, sim, o curso de Pedagogia da UnB tem a potencialidade de oferecer os conhecimentos musicais necessários para o trabalho do pedagogo com esta área de conhecimento. Potencialidade, porque as disciplinas são de cunho optativo e, portanto, não se garante que todos irão cursar tais disciplinas, fragilizando, de certa forma, a sua formação.

Como possibilidade de pesquisas futuras, vislumbra-se uma observação e análise da prática dos professores egressos, que poderá revelar como e se esse trabalho vem sendo realizado na EI, no DF.

\section{REFERENCIAS}

BELLOCHIO, Claudia R.; WEBER, Vanessa; SOUZA, Zelmielen Adornes de. Música e unidocência: pensando a formação e as práticas de professores de referência. Revista da FAEEBA, Salvador, v. 26, n. 48, p. 205-221, 2017.

BRASIL. Lei n. 9.394 de 20 de dezembro de 1996. Estabelece as Diretrizes e Bases da Educação Nacional. Diário Oficial da União: seção 1, Brasília, DF, ano 134, n. 248, p. 7-65, 20 nov. 1996.

Lei $\mathrm{n}^{\circ} 13.278$, de 2 de maio de 2016. Altera o $\S 6^{\circ}$ do art. 26 da

Lei $\mathrm{n}^{\circ}$ 9.394, de 20 de dezembro de 1996, que fixa as diretrizes e bases da educação nacional, referente ao ensino da arte. Diário Oficial da União: seção 1, Brasília, DF, ano 153, n. 83, p. 1, 3 maio 2016.

CHARMAZ, Kathy. A construção da teoria fundamentada: guia prático para análise qualitativa. Porto Alegre: Artmed, 2009.

DISTRITO FEDERAL. Secretaria de Estado de Educação do Distrito Federal. Currículo em movimento da educação básica: educação infantil. Brasília, DF: SEEDF, 2014. 
FERNANDEZ, Carmen. PCK - Conhecimento Pedagógico do Conteúdo: perspectivas e possibilidades para a formação de professores. In: ENCONTRO NACIONAL DE PESQUISA EM EDUCAÇÃO EM CIÊNCIAS, 8., Campinas, 2011. Atas [...] São Paulo: Abrapec, 2011. p. 1-12.

FRANÇA, Cecília C.; SWANWICK, Keith. Composição, apreciação e performance na educação musical: teoria, pesquisa e prática. Em Pauta, Porto Alegre, v. 13, n. 21, p. 5-41, 2002.

GIL, Antônio Carlos. Como elaborar projetos de pesquisa. 5. ed. São Paulo: Atlas, 2010.

GIMENO SACRISTÁN, José. O currículo: uma reflexão sobre a prática. 3. ed. Porto Alegre: Penso, 2017.

NIÉRI, Débora. A pesquisa brasileira em educação musical infantil: tendências teórico-metodológicas e perspectivas. 2014. Tese (Doutorado em Música) - Instituto de Artes, Universidade Estadual Paulista Júlio de Mesquita Filho, São Paulo, 2014.

SHULMAN, Lee S. Conhecimento e ensino: fundamentos para a nova reforma. Tradução de Leda Beck. Cadernos Cenpec, São Paulo, v. 4, n. 2, p. 196-229, 2014.

UNIVERSIDADE DE BRASÍLIA. Faculdade de Educação. Projeto acadêmico do curso de pedagogia. Brasília, DF: UnB, 2002.

Faculdade de Educação. Relação de disciplinas ofertadas. Brasília, DF: UnB, 2018.

VIANA, Érica. A linguagem musical na educação infantil: reflexões e possibilidades. 2016. Dissertação (Mestrado em Processos de Ensino, Gestão e Inovação) - Centro Universitário de Araraquara, Araraquara, 2016. 
Sara Paraguassú Santos do Vale é doutoranda em Educação na Universidade Federal de Juiz de Fora (UFJF). Possui mestrado em Música pela Universidade de Brasília (UnB) e especialização em Arte, Educação e Tecnologias contemporâneas. É licenciada em Pedagogia e Música e é professora formadora no Centro de Vivências Lúdicas - Oficina Pedagógica, da Secretaria de Estado de Educação do Distrito Federal. https://orcid.org/0000-0002-2499-9838 